\title{
1980s Camelot
}

\author{
Stuart L. Schreiber ${ }^{1}$
}

Received: 4 March 2019 / Accepted: 5 March 2019 / Published online: 27 May 2019

(c) The Author(s), under exclusive licence to the Japan Antibiotics Research Association 2019

Samuel "Sam" Danishefsky is a legend in organic chemistry. His impact is far and wide-but his specialness goes well beyond his prodigious scientific accomplishments. In the 1980 s, I was fortunate enough to see and experience this first-hand as a young academic in need of a guiding light, which Sam provided during that formative decade.

Nearly every day in that special time, Sam reinforced the magic and awesomeness of science, and how, when coupled to family, friends and one's belief system, it was key to living a happy and fulfilling life. There was a simplicity and consistency to how Sam viewed chemistry and our chemistry community - he valued creativity and innovation and trusted his judgement in people. To this day, when Sam sees something special in a person, he nurtures and supports them. He is the quintessential mentor. He brings that same passion and dedication to his family and faith.

I know first-hand the power of Sam's special qualities. They enabled me to feel sufficiently confident to launch a career in science. I hope this is an appropriate venue to share some personal reflections.

I will forever be grateful that Sam Danishefsky saw something in me not seen by others late in the year 1980 . My naivete and lack of accomplishment were the most remarkable aspects of my job application and interview for a position on the Yale faculty; nevertheless, with Sam as the leader of the department, an offer was made that I happily accepted (after a moment of misunderstanding - see below). I am even more grateful for the environment he created at
Yale during that period that allowed me to rise above my shortcomings. Perhaps most importantly, Sam's extraordinary passion and energy for organic chemistry and warmth, friendship and support provided a vaccine against apathy, one that happily remains in place to this day.

That readers do not think that I am being modest about my naivete, I will share two short anecdotes about my joining the Yale faculty. While interviewing, I was asked what funding agencies I planned to approach for grants. Since I could not name one, I was forced to say "I know they exist and that others have received funding, so I am certain that I too will receive funding." When the Chair called me to offer a position and reported that the "the startup would be $\$ 35,000 "$ ", I responded that I had to decline since I was penniless and would never be able to pay such an entry fee. When I was told that Yale would actually provide me that amount, I responded "No f---ing way!"

Despite the rawness of my being, Sam embraced me from our very first encounter. He made me feel special. He engaged me regularly, especially in the most remarkable almost daily scientific whirlwind meetings in his office, where every aspect one could imagine about organic chemistry and science was explored, debated, absorbed and enjoyed. Through this scientific engagement of a master and a very raw apprentice, I learned Sam's magic elixir and, most importantly, how to become a scientist. For this and his friendship, I will be forever grateful. The well of love in my heart is very deep for Sam Danishefsky.
Stuart L. Schreiber

stuart_schreiber@harvard.edu

1 Harvard University, Broad Institute, Cambridge, MA, USA 